\title{
Hydrothermal liquefaction of demineralized wastewater algal biomass
}

\author{
Rowena Carpio ${ }^{\mathrm{a}, \mathrm{b}, \mathrm{c}, *}$, Chih-Ting Kuo ${ }^{\mathrm{c}}$, Rizalinda de Leon ${ }^{\mathrm{b}}$, Lance Charles \\ Schideman ${ }^{\mathrm{d}}$, Yuanhui Zhang ${ }^{\mathrm{c}}$ \\ ${ }^{a}$ Department of Chemical Engineering, University of the Philippines Los Baños, Laguna 4031, Philippines \\ ${ }^{b}$ Department of Chemical Engineering, University of the Philippines Diliman, Quezon City 1101, Philippines \\ ${ }^{c}$ Department of Agricultural and Biological Engineering, University of Illinois at Urbana-Champaign, Urbana, IL 61801, USA \\ ${ }^{d}$ Illinois Sustainable Technology Center, University of Illinois at Urbana-Champaign, Urbana, IL 61801, USA
}

\begin{abstract}
The use of high-ash containing biomass for energy applications leads to serious problems during the conversion process and affects the quality of the resulting fuel products. In this study, the effect of demineralization treatments on the hydrothermal liquefaction (HTL) of wastewater algal biomass (WAB) was investigated. Three different acid treatments were selected in this study: acetic acid (AA), formic acid (FA), and sulfuric acid (SA). The HTL product distribution and the quality and chemical composition of the biocrude oil obtained from the treated and untreated biomass (UBM) were compared. HTL experiments were conducted using a $40-\mathrm{mL}$ tubular reactor at a reaction temperature of $300{ }^{\circ} \mathrm{C}$ for a retention time of 60 min under an initial headspace pressure of 100 psi, with pure $\mathrm{N}_{2}$ used as the process gas. The results revealed that the demineralization treatments significantly improved the biocrude oil yield from $17 \%$ daf (dry, ash-free weight) up to $25 \%$ daf and the aqueous phase product yield from $50 \%$ daf up to $61 \%$ daf, while there was no significant effect on the yield of the gaseous products (6\%-7\% daf). The solid residue yield was lower in the treated biomass (7\%-15\% daf) in comparison with that from the UBM (26\% daf). The highest biocrude oil yield (25\% daf) was obtained from AA and FA. However, the highest biocrude oil energy recovery (ER) was obtained from FA $(41.83 \% \pm 1.87 \%)$, which was $~ 52 \%$ higher than that from the UBM. The ultimate, GC-MS and thermogravimetric analyses showed that the biocrude oils obtained from demineralized biomass were comparable in quality and did not vary much from the biocrude oil obtained from the UBM.
\end{abstract}

Keywords: Hydrothermal liquefaction, algal, demineralization

\section{Introduction}

Microalgae have been successfully utilized for wastewater treatments because of their ability to use inorganic nitrogen and phosphorus for their growth and because of their capacity to remove heavy metals and toxic organic compounds [1]. Algal-based wastewater treatment produces a large amount of biomass that could cause severe secondary environmental problems, including the release of odors and groundwater contamination, if not treated properly. Considering the demand for biowaste treatment, such as wastewater algal biomass (WAB) and new renewable energy sources, hydrothermal liquefaction (HTL) provides a promising solution for solving both the environmental and energy problems. HTL is a suitable choice for wet biomass, e.g., algal biomass, because it does not require energy-intensive drying and has the ability to convert mixed-culture microalgal biomass and mixed biomass feed into fuel oil.

This research was conducted to help address some key bottlenecks in the realization of an algal biorefinery system known as "Environmental-Enhancing Energy" (E2E). E2E is a promising system for

\footnotetext{
*Manuscript received July 25, 2017; revised December 30, 2017.

Corresponding author. Tel.: +63-928-399-5419; E-mail address: rowena.carpio@up.edu.ph

doi: $10.12720 /$ sgce.7.1.13-23
} 
algal biofuel production that synergistically integrates algal wastewater treatment with the HTL of wastewater biosolids and algae into biocrude oil [2]. It is also based on the full use of feedstock components by maximizing the recovery of hydrocarbons and reusing nutrients stored in the post-HTL aqueous phase using algae cultivation. In the context of E2E, biocrude oil is produced from algae via HTL. The post-HTL wastewater is cleaned, and carbon dioxide is captured via algae cultivation. The additional algal biomass generated is further converted into biocrude oil via HTL. The E2E paradigm realizes multiple stages of algae production and biofuel conversion and simultaneously cleans wastewater and captures carbon dioxide [3].

Algal biomass harvested from wastewater typically contains 30\%-50\% dw (dry weight basis) ash [4]. High ash containing biomass presents a number of problems that reduces the conversion efficiency when used for bioenergy applications. The ash in biomass is due to the presence of alkali and alkaline earth metals (AAEMs), such as $\mathrm{K}, \mathrm{Ca}, \mathrm{Mg}, \mathrm{Fe}, \mathrm{Al}$, and $\mathrm{Si}$. The effects of AAEMs in fuel have been extensively studied for combustion and gasification applications. Biomass rich in AAEMs forms a complex reaction with other inorganic elements (e.g. Si and $\mathrm{Cl}$ ) that effectively lowers the melting point of the ash during combustion, which causes slagging and accelerated corrosion problems [5]-[9]. Wang et al. [10] reported that AAEMs in biomass cause a deleterious effect on the hydrocarbon yield using catalytic pyrolysis. High ash containing mixed-algal biomass tends to favor the production of aqueous or solid products over biocrude oil in HTL [11].

Given the deleterious effect of the high ash concentration in biomass, a number of researchers have explored several techniques to remove (or reduce) the AAEM constituents from biomass prior to conversion [5], [12]-[15], including size fractionation and leaching. In most cases, demineralization leads to the undesirable loss of organic matter from biomass. However, the severity of this loss depends on the structure of the biomass and the treatment employed. The removal of AAEMs is expected to affect the physicochemical characteristics of biomass and influence the performance of biomass during conversion.

This study investigates the effect of demineralization treatments using acid leaching on the conversion of WAB via HTL. Three different acids were used in the study: acetic acid (AA), formic acid (FA), and sulfuric acid (SA). The study focuses on the impact of the treatments on HTL product distribution and the quality of the biocrude oil products using elemental analysis, ER, GC-MS analysis, and boiling point distribution. Although the HTL of algal biomass has been extensively studied, research on algal biomass harvested from wastewater is still limited and much less is reported on the HTL of demineralized waste biomass. The results obtained from this study will not only benefit biomass used in the E2E scheme but also other high ash containing biomass, such as macroalgae, microalgae from water bloom, and livestock/agricultural residues.

\section{Materials and Methods}

\subsection{Raw materials}

The WAB used in this study was collected from the fixed-film algae cultivation system at the Department of Agricultural and Biological Engineering, University of Illinois Urbana-Champaign (UIUC), USA. The system was used to treat wastewater generated by the UIUC Swine Research Center. The biomass contains various species of microalgae, bacteria, insect larvae, and other microorganisms. The biomass was collected using 100-micron nylon screen filter bags and dewatered to achieve a $10 \%-15 \%$ solid (w/w) algal paste, which was then dried in a convection oven at $105{ }^{\circ} \mathrm{C}$ for $24 \mathrm{~h}$. The dry biomass was pulverized, sieved for particles larger than 300 microns, and then stored in a desiccator at room temperature $\left(25^{\circ} \mathrm{C}\right)$ prior to use.

\subsection{Demineralization}

Demineralization of WAB was conducted using a leaching method with different dilute acid solutions: AA $(10 \% \mathrm{w} / \mathrm{w}), \mathrm{FA}(5 \% \mathrm{w} / \mathrm{w})$, and SA $(1 \% \mathrm{w} / \mathrm{w})$. The biomass was soaked in the leaching agent at 20$\mathrm{mL} / \mathrm{g}$ dry biomass for 10-15 min. After leaching, the algal biomass and the leachate were separated by 
vacuum filtration using a 55-mm Whatman filter paper, Grade 42 (Whatman 1442-055). The leached samples were washed with an excess amount of deionized water until the $\mathrm{pH}$ value became neutral. The treated biomass samples were dried in a convection oven at $105{ }^{\circ} \mathrm{C}$ for $24 \mathrm{~h}$. The resulting biomass was pulverized and then stored in a desiccator at room temperature $\left(25^{\circ} \mathrm{C}\right)$ prior to use. Table 1 shows the characteristics of WAB before and after demineralization.

Table 1. The characteristics of the untreated and demineralized wastewater algal biomass (WAB).

\begin{tabular}{lcccc}
\hline Characteristics & UBM & AA & FA & SA \\
\hline Ash $(\% \mathrm{dw})$ & $40.07 \pm 0.64$ & $30.05 \pm 0.07$ & $25.70 \pm 0.02$ & $29.55 \pm 0.21$ \\
Crude Protein $(\% \mathrm{dw})$ & 30.07 & 35.92 & 38.27 & 34.97 \\
Crude lipid $(\% \mathrm{dw})^{\text {Total carbohydrate }}(\% \mathrm{dw})$ & 0.58 & 0.26 & 0.19 & 0.61 \\
$\mathrm{C}(\% \mathrm{dw})$ & 29.28 & 33.82 & 35.84 & 34.87 \\
$\mathrm{H}(\% \mathrm{dw})$ & $32.06 \pm 1.92$ & $38.04 \pm 0.41$ & $40.04 \pm 0.93$ & $37.9 \pm 0.64$ \\
$\mathrm{~N}(\% \mathrm{dw})$ & $3.99 \pm 0.1$ & $4.56 \pm 0.13$ & $4.62 \pm 0.06$ & $4.68 \pm 0.08$ \\
$\mathrm{O}^{2}(\% \mathrm{dw})$ & $4.54 \pm 0.13$ & $5.50 \pm 0.16$ & $5.63 \pm 0.01$ & $5.57 \pm 0.16$ \\
$\mathrm{~N} / \mathrm{C}$ atomic ratio & $19.34 \pm 1.7$ & $21.85 \pm 0.69$ & $24.02 \pm 0.99$ & $22.31 \pm 0.88$ \\
$\mathrm{H} / \mathrm{C}$ atomic ratio & 0.12 & 0.12 & 0.12 & 0.13 \\
O/C atomic ratio & 1.49 & 1.44 & 1.38 & 1.48 \\
HHV $(\mathrm{MJ} / \mathrm{kg})$ & 0.45 & 0.43 & 0.45 & 0.44 \\
\hline
\end{tabular}

${ }^{1}$ By the difference: Total carbohydrate $(\% \mathrm{dw})=100 \%-$ Ash $(\% \mathrm{dw})-$ Crude Protein $(\% \mathrm{dw})-$ Crude Lipid $(\% \mathrm{dw})$

${ }^{2}$ By the difference: $\mathrm{O}(\% \mathrm{dw})=100 \%-\mathrm{Ash}(\% \mathrm{dw})-\mathrm{C}(\% \mathrm{dw})-\mathrm{H}(\% \mathrm{dw})-\mathrm{N}(\% \mathrm{dw})$

\subsection{HTL experiment}

HTL experiments were conducted in a $40-\mathrm{mL}$ tubular reactor. The reactor was assembled using Swagelok tubing and parts. The body of the reactor was constructed from stainless-steel tubing with an external diameter of $3 / 4$ in and a wall thickness of $0.109 \mathrm{in}$. The tubing was rated up to $5800 \mathrm{psi}(40 \mathrm{MPa})$ at $-28{ }^{\circ} \mathrm{C}-37{ }^{\circ} \mathrm{C}$ with a temperature adjustment multiplier of $0.85(34 \mathrm{MPa})$ at $315{ }^{\circ} \mathrm{C}, 0.79(31.6 \mathrm{MPa})$ at $426{ }^{\circ} \mathrm{C}$, and $0.76(30.3 \mathrm{MPa})$ at $537{ }^{\circ} \mathrm{C}$. The tubing was cut to $5 \frac{1 / 2}{2}$ in to provide a reactor volume of 40 $\mathrm{mL}$. One end of the tubing was sealed with a cap using Swagelok fitting, and the other end was attached to a Swagelok high-pressure valve $\left(37.5 \mathrm{MPa}\right.$ at $\left.537{ }^{\circ} \mathrm{C}\right)$. All necessary adaptors were made of stainless steel. A total of $12 \mathrm{~g}$ of feedstock containing $25 \%$ dry algal biomass and $75 \%$ deionized water by weight was loaded into the reactor vessel. The reactor was sealed, and the reactor headspace was purged with pure nitrogen three times before finally charging with an initial pressure of 100 psi using pure nitrogen gas. The reactor was then placed inside a pre-heated $\left(300^{\circ} \mathrm{C}\right)$ muffle furnace for $60 \mathrm{~min}$ at a maintained temperature of $300{ }^{\circ} \mathrm{C}$. At the end of the process, the reactor was rapidly cooled by quenching it in a bucket full of water.

\subsection{HTL product recovery and estimation}

Product recovery was performed by carefully releasing the gas products from the reactor after cooling was completed. The gas product yield was estimated by the ideal gas equation using the initial and final system pressures. Samples of the gas product were collected in a vacuum vial and stored in a chiller until use. The reaction mixture containing the solid and liquid products was poured out of the reactor into a small flask. The reactor was then washed three times with $10 \mathrm{~mL}$ of dichloromethane (DCM), and the extracts were added to the same flask containing the reaction mixture. The HTL reaction mixture with DCM was then filtered using a vacuum filtration to separate the solids. The filter cake was thoroughly washed with an additional amount of DCM and then dried in a convection oven at $105{ }^{\circ} \mathrm{C}$ for $24 \mathrm{~h}$. The resulting dry mass constituted the solid residue fraction. The filtrate was transferred to a separatory funnel and allowed to settle for $\sim 15 \mathrm{~min}$. The resulting mixture formed two separate layers: the aqueous phase on top and the DCM phase, which contains the biocrude oil at the bottom. The DCM phase was collected in a pre-weighed foil cup. Biocrude oil was obtained by evaporating DCM in a fume hood for at least $12 \mathrm{~h}$. The aqueous phase was collected and stored until use.

The product yields were estimated by gravimetry and then reported as an average value and standard deviation from at least two runs (in \% daf). The yields of biocrude oil, gas, solid, and aqueous phase were 
calculated using the following equations:

$$
\begin{aligned}
& \text { Biocrude oil (\%daf) }=\frac{M_{\text {oil }}}{M_{F S}(1-A)} \times 100 \\
& \text { Gas yield (\%daf) }=\frac{\left(\frac{n_{f}}{M W_{G}}-\frac{n_{i}}{M W_{N_{2}}}\right)}{M_{F S}(1-A)} \times 100 \\
& \text { Solid residue }(\% \text { daf })=\frac{M_{s}-M_{F S}(\mathrm{~A})}{M_{F S}(1-A)} \times 100
\end{aligned}
$$

where $M_{F S}$ is the mass of the feedstock, $M_{\text {oil }}$ is the mass of biocrude oil, $A$ is the $\%$ ash content of the feedstock, $n_{f}$ and $n_{i}$ are the number of moles of the gas phase before and after the HTL reaction, respectively, both computed by means of the ideal gas equation using the initial and final system pressures, $M W_{G}$ is the molecular weight of the gas product, $M W_{N_{2}}$ is the molecular weight of nitrogen gas, and $M_{S}$ is the mass of solid left after the HTL reaction.

\subsection{Analyses}

The ash content of biocrude oil was measured as the residue after burning for $3 \mathrm{~h}$ at $575{ }^{\circ} \mathrm{C} \pm 25{ }^{\circ} \mathrm{C}$ in a muffle furnace. The CHN composition was tested by the Microanalysis Lab at the University of Illinois (Urbana, IL) using a CHN analyzer (CE-440, Exeter Analytical Inc., MA). The higher heating value (HHV) was calculated using Dulong's equation (5):

$$
H H V(M J / K g)=0.3383 C+1.443(H-O / 8)
$$

where $C, H, N$, and $O$ are the carbon, hydrogen, nitrogen, and oxygen mass \% (dry weight basis), respectively.

The chemical composition of the biocrude samples was analyzed by injecting $1 \mu \mathrm{L}$ of the sample in split mode (10:1) into a GC-MS system (Agilent Inc, CA, USA) comprising an Agilent 6890 gas chromatograph, an Agilent $5973 \mathrm{MSD}$, an HP-5MS capillary column $(30 \mathrm{~m} \times 0.25 \mathrm{~mm}$ I.D.; fim thickness $=0.25 \mathrm{~mm}$ ), and an Agilent 7683B autosampler (Agilent Inc., CA, USA). The inlet temperature was set to $280{ }^{\circ} \mathrm{C}$, the MS interface was set to $230{ }^{\circ} \mathrm{C}$, and the ion source temperature was adjusted to $230{ }^{\circ} \mathrm{C}$. The helium carrier gas was maintained at a constant flow rate of $1 \mathrm{~mL} / \mathrm{min}$. The temperature program was $3 \mathrm{~min}$ at $50{ }^{\circ} \mathrm{C}$, followed by an oven temperature ramp of $5{ }^{\circ} \mathrm{C} / \mathrm{min}$ to $310{ }^{\circ} \mathrm{C}$ for a final duration of $3 \mathrm{~min}$. The mass spectrometer was operated in positive electron impact (EI) mode at an ionization energy of $69.9 \mathrm{eV}$ over the $\mathrm{m} / \mathrm{z}$ scan range 30-800. To allow a comparison between the samples, all data were normalized using pentadecanoic acid methyl ester $(0.5 \mu \mathrm{M})$ as an internal standard. The instrument variability was within the standard acceptance limit of 5\%. The spectra of all chromatogram peaks were evaluated using the AMDIS 2.71 program (NIST, Gaithersburg, MD, USA) and compared with the EI mass spectrum from the NIST mass spectral database (NIST08) and W8N08 library (John Wiley \& Sons, Inc., USA).

The boiling point range distribution of the biocrude oil samples was estimated using thermogravimetric analysis (TGA; Q50 TGA, TA Instruments, Schaumburg, IL). During each test, the samples were heated in the furnace of the analyzer from room temperature to $800{ }^{\circ} \mathrm{C}$ at a heating rate of $10{ }^{\circ} \mathrm{C} / \mathrm{min}$. For each test, approximately $20 \mathrm{mg} \pm 0.1 \mathrm{mg}$ of the dry samples were used. Pure nitrogen (99.99\% purity) was used as the carrier gas during all experiments to suppress the mass transfer effect to a minimum. The flow rate of nitrogen used for the balance was maintained at $40 \mathrm{~mL} / \mathrm{min}$, and the flow rate for the sample was maintained at $60 \mathrm{~mL} / \mathrm{min}$. 


\subsection{Energy recovery}

The energy recovery (ER) of the biocrude oil samples was calculated using the following equation:

$$
E R=\frac{H H V_{o i l}\left(M_{o i l}\right)}{H H V_{F S}\left(M_{F S}\right)} \times 100
$$

where $H H V_{\text {oil }}$ is the HHV of the biocrude oil, $M_{\text {oil }}$ is the mass of the biocrude oil, $H H V_{F S}$ is the HHV of the feedstock, and $M_{F S}$ is the mass of the feedstock.

\section{Results and Discussion}

\subsection{The effects of demineralization on the HTL product distribution}

From Figure 1, it can be seen that the solid residue yield obtained from demineralized biomass was significantly lower $(7.42 \%-15.03 \%$ daf) than that from the UBM $(25.55 \%$ daf). The increase in the conversion of the feedstock benefits both the biocrude oil and the aqueous phase fraction. The biocrude oil yield from demineralized biomass was higher (20.98\%-25.34\% daf) than that from the UBM (17.01\% daf). A similar result was observed with regard to the aqueous phase yield obtained from the demineralized biomass $(57.90 \%-60.65 \%$ daf) and UBM (50.29\% daf), while demineralization did not show any significant effect on the gaseous product yield $(6.08 \%-7.15 \%$ daf). The increase in the conversion was probably due to the more effective dissolution of the biomass organic constituents as a result of the increased surface area of the biomass particles following demineralization. In addition, the lower ash content indicated that more organic material was available for conversion and reduced the amount of unwanted ash particles that interfered with the HTL reaction. It is also interesting to note that AA and FA yielded the same amount of biocrude oil despite the significant differences in their ash content $(30.05 \% \mathrm{dw}$ and $25.70 \% \mathrm{dw}$, respectively; Table 1). Meanwhile, AA and SA contained the same amount of ash (30.05 and $29.55 \% \mathrm{dw}$, respectively; Table 1), but AA yielded a higher biocrude oil (24.47\% daf) compared to that of SA (20.98\% daf). This result reveals that the ash content interacts with the volatile components in the samples during the HTL process.

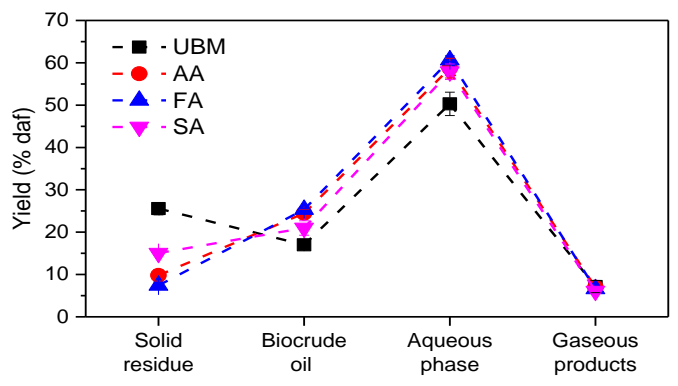

Figure 1. The hydrothermal liquefaction (HTL) product distribution of the untreated and demineralized (acid-treated) biomass. UBM: untreated biomass; AA: acetic acid; FA: formic acid; SA: sulfuric acid; the error bars indicate standard deviation $(\mathrm{n} \geq 2)$.

\subsection{The ash content, elemental analysis, $H H V$, and ER of biocrude oils}

Table 2 summarizes the ash content, elemental analysis, HHV, and ER of the biocrude oil samples derived from the UBM and demineralized biomass. When compared with the UBM, the ash content in the biocrude oil obtained from all the demineralized biomass samples was significantly lower. The CHNO composition of the biocrude oil from all the samples and the values obtained for the atomic ratio of N/C, $\mathrm{H} / \mathrm{C}$, and $\mathrm{O} / \mathrm{C}$ were comparable. When compared to the original feedstocks (see Table 1), the values of 
the atomic ratio of $\mathrm{N} / \mathrm{C}$ and $\mathrm{O} / \mathrm{C}$ in the biocrude oil samples were much lower, while the high value of the atomic ratio of $\mathrm{H} / \mathrm{C}$ was maintained. The HHV of the biocrude oil obtained from the UBM and all the demineralized biomass samples were comparable $(\sim 35 \mathrm{MJ} / \mathrm{Kg})$, which is lower than that of the petroleum crude, which has an average HHV of $42.7 \mathrm{MJ} / \mathrm{Kg}$ [16]. In terms of ER, only $22.58 \%$ of the energy present in the UBM was recovered in the form of bio-oil, while with the demineralized biomass samples, ER of the biocrude oils was higher by $23 \%-42 \%$. The increase in ER was mainly due to the increase in the biocrude oil yield. The highest ER value $(41.83 \% \pm 1.87 \%)$ was obtained from FA.

Table 2. The characteristics of the biocrude oil obtained from the hydrothermal liquefaction (HTL) of the untreated and demineralized $\mathrm{WAB}$ at $300^{\circ} \mathrm{C}$ after $60 \mathrm{~min}$.

\begin{tabular}{lcccc}
\hline Characteristics & UBM & AA & FA & SA \\
\hline Ash $(\% \mathrm{dw})$ & $1.14 \pm 0.02$ & $0.27 \pm 0.00$ & $0.46 \pm 0.01$ & $0.39 \pm 0.01$ \\
$\mathrm{C}(\% \mathrm{dw})$ & $71.7 \pm 0.21$ & $72.35 \pm 0.15$ & $72.62 \pm 0.12$ & $72.63 \pm 0.07$ \\
$\mathrm{H}(\% \mathrm{dw})$ & $9.13 \pm 0.03$ & $8.83 \pm 0.05$ & $8.84 \pm 0.01$ & $8.97 \pm 0.02$ \\
$\mathrm{~N}(\% \mathrm{dw})$ & $7.17 \pm 0.01$ & $6.97 \pm 0.02$ & $7.00 \pm 0.00$ & $7.05 \pm 0.01$ \\
$\mathrm{O}^{1}(\% \mathrm{dw})$ & $10.85 \pm 0.24$ & $11.60 \pm 0.22$ & $11.09 \pm 0.11$ & $10.97 \pm 0.08$ \\
$\mathrm{~N} / \mathrm{C}$ atomic ratio & 0.09 & 0.08 & 0.08 & 0.08 \\
$\mathrm{H} / \mathrm{C}$ atomic ratio & 1.53 & 1.46 & 1.46 & 1.48 \\
$\mathrm{O} / \mathrm{C}$ atomic ratio & 0.11 & 0.12 & 0.11 & 0.11 \\
$\mathrm{HHV}(\mathrm{MJ} / \mathrm{kg})$ & $35.32 \pm 0.15$ & $34.96 \pm 0.16$ & $35.17 \pm 0.04$ & $35.37 \pm 0.07$ \\
$\mathrm{ER}(\%)$ & $27.58 \pm 1.84$ & $38.67 \pm 0.27$ & $41.83 \pm 1.87$ & $33.79 \pm 3.86$ \\
\hline
\end{tabular}

${ }^{1}$ Calculated by the difference: $\mathrm{O}(\% \mathrm{dw})=100 \%-\mathrm{Ash}(\% \mathrm{dw})-\mathrm{C}(\% \mathrm{dw})-\mathrm{H}(\% \mathrm{dw})-\mathrm{N}(\% \mathrm{dw})$

Figure 2 shows the classification of the biocrude oil samples and corresponding feedstocks based on the Van Krevelen diagram. The H/C, N/C, and O/C atomic ratios obtained for the biocrude oil samples and corresponding feedstocks are listed in Tables 1 and 2, respectively. The plots of the H/C and O/C atomic ratios of several types of conventional fuels and biopolymers reported in the literature are also reported for comparison. Results reveal that WAB approached the quality of lignin in terms of the molar ratios of $\mathrm{H} / \mathrm{C}$ and $\mathrm{O} / \mathrm{C}$, following the demineralization pretreatment, while the biocrude oils obtained are similar to bitumen in terms of the H/C ratio only. In comparison with petroleum crude oil, the biocrude oil obtained would need upgrading to reduce the ratios of $\mathrm{O} / \mathrm{C}$ and N/C and increase the H/C ratio. The high oxygen and nitrogen contents are the primary factors that distinguish biocrude oil from petroleum crudes; however, an upgrading process to lower the heteroatom content represents a significant challenge in the biofuel industry [17].

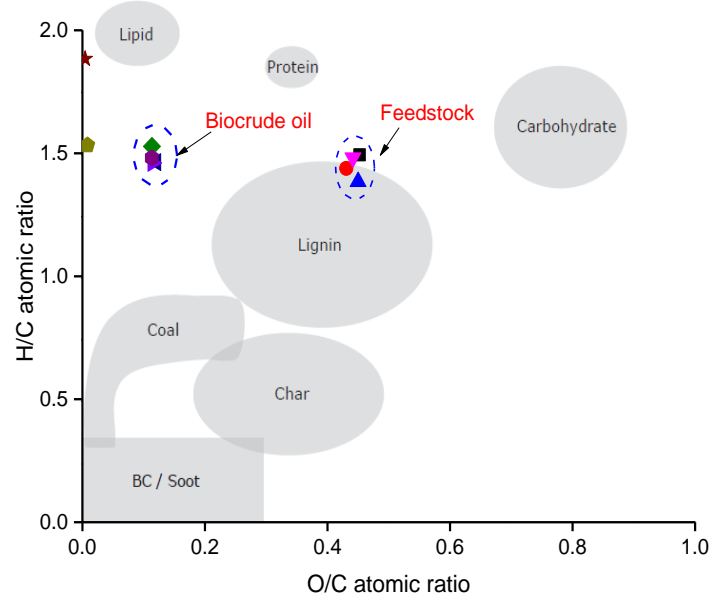

(a)

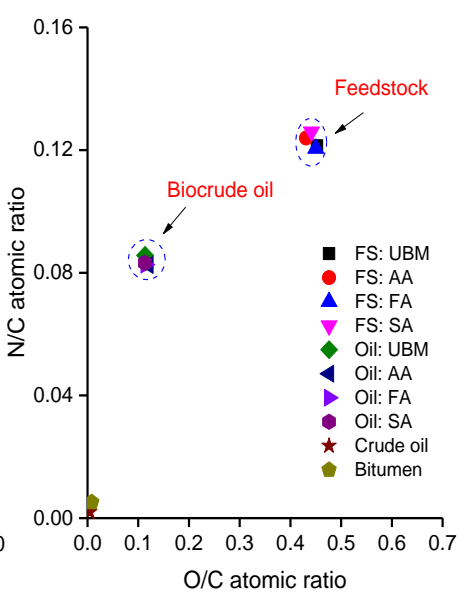

(b)

Figure 2. The Van Krevelin plots of the untreated and acid-treated biomass samples and their corresponding biocrude oils, along with typical biopolymers, biomass, and pyrogenic materials (gray shaded areas are adopted from [18]): (a) $\mathrm{H} / \mathrm{C}$ atomic ratio vs. $\mathrm{O} / \mathrm{C}$ atomic ratio and (b) N/C atomic ratio vs. $\mathrm{O} / \mathrm{C}$ atomic ratio. 


\subsection{The chemical composition of biocrude oils}

A list of the major components (relative total peak area $>1 \%$ ) of the biocrude oil samples identified using GC-MS analysis is presented in Appendix A. There were approximately 33-36 different compounds identified from the biocrude oil samples, which comprised $71 \%-77 \%$ of the total ion chromatogram (TIC) peak area. All compounds identified using GC-MS were classified into several groups: hydrocarbons, oxygenates, nitrogenates, $\mathrm{O}-$ and $\mathrm{N}$-heterocycles, and aromatic compounds. The hydrocarbons include saturated, unsaturated, and cyclic hydrocarbons; the oxygenates include carboxylic acids/fatty acids, esters, aldehydes, ketones, and alcohols; the nitrogenates include amines and amides; the $\mathrm{O}-$ and N-heterocycles include oxygenated and nitrogenated compounds, which contain both oxygen and nitrogen; and aromatic compounds include monoaromatics (benzene, toluene, phenol, and other simple phenyl derivatives) and polyaromatics (naphthalene, indene, and their derivatives) [19]. The results are presented in Figure 3.

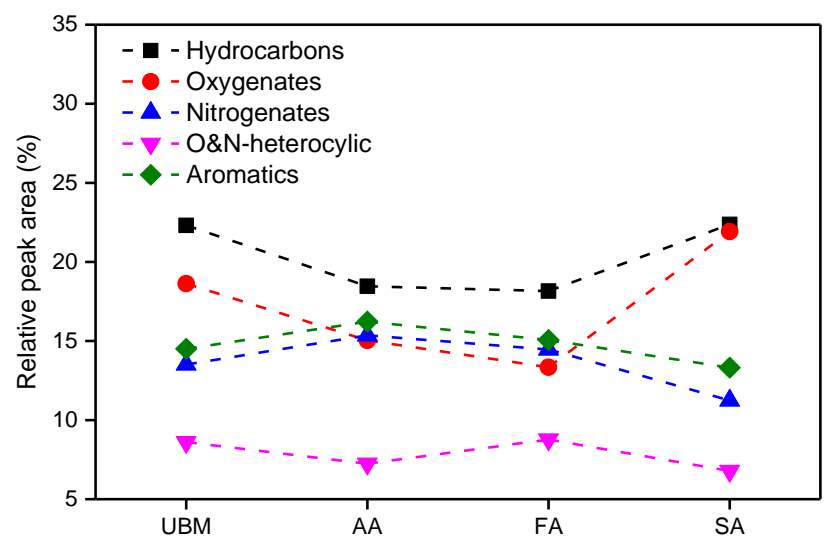

Figure 3. The distribution of the key organic compound groups found in the biocrude oils derived from the untreated and demineralized biomass.

Hydrocarbons are the most abundant compounds present in all biocrude oil samples. When compared with the biocrude oil obtained from the UBM (22.31\%), the abundance of hydrocarbons from AA and FA was lower $(18.46 \%$ and $18.16 \%$, respectively), while it does not change in SA $(22.37 \%)$. Hexadeceneframed alkenes are the most abundant hydrocarbons in all biocrude oil samples, but these compounds were lower in abundance in all the biocrude oils obtained from the demineralized biomass in comparison with the amount of compounds obtained from the UBM. The oxygenates were also abundant in the UBM biocrude oil (18.63\%), and the amount of these compounds increased in the SA bio-oil and decreased in both the AA and FA bio-oils (15.04 and $13.34 \%$, respectively). The decline in oxygenates improved the properties of the biocrude oil related to its storage stability. Pentadecanoic acid methyl ester was detected in all biocrude oil samples. However, this compound was introduced into the samples prior to the GC-MS analysis as an internal standard. No other fatty acid methyl ester was detected in the samples, except in the SA biocrude oil, which also contained palmitic and stearic acid butyl esters. Remarkably, even though there were only $<1 \% \mathrm{dw}$ crude lipid in all biomass feedstocks, the hydrocarbons, fatty acid, and derivatives found in the biocrude accounted for 33\%-45\% of the TIC peak area. Nitrogenates, such as amines and amides, in the biocrude oil mainly result from the decarboxylation and deamination of the amino acids generated as a result of the hydrolysis of the proteins [20] in the feedstock. When compared with the UBM (13.52\%), the nitrogenates are higher in both the AA (15.36\%) and FA biocrude oils $(14.46 \%)$ and lower in the SA biocrude oil (11.24\%). The presence of nitrogenated compounds in the biocrude oils is not desirable as it poses a challenge during upgrading [21]. The $\mathrm{N}$ - and O-containing compounds were also detected in the biocrude oil samples, and accounted for $6 \%-9 \%$ of the TIC peak 
area. $\mathrm{N}$-acetylpyrrolidine was the most abundant $\mathrm{N}$ - and $\mathrm{O}$-containing compound in all biocrude oil samples. Relative to the UBM (3.19\%), N-acetylpyrrolidine was higher in both the AA (5.15\%) and FA (3.39\%) biocrude oils and lower in the SA biocrude oil (2.7\%). Aromatic compounds accounted for approximately $13 \%-16 \%$ of the TIC peak area in all biocrude oil samples. Biocrude oil obtained from AA has the highest abundance but least variety of aromatic compounds. The aromatic compounds mainly consisted of $\mathrm{N}$-containing rings, such as indole, 5-methyl-1H-indole, $\mathrm{N}$-phenethyl-acetamide, and 1methyl-9H-pyrido[3,4-b]indole. These compounds could be generated via the Maillard reaction between amines and carbohydrates [22].

\subsection{Boiling point distribution of biocrude oils}

The boiling point distribution of the biocrude oil samples was estimated using a TGA by heating the samples to $800{ }^{\circ} \mathrm{C}$ at a constant heating rate of $10{ }^{\circ} \mathrm{C} / \mathrm{min}$ under $\mathrm{N}_{2}$ atmosphere. TGA applied in simulated distillation is regarded as "miniature distillation," although some thermal degradation is likely. It provides an estimate of the boiling range of heavy oil [16]. Figure 4 shows that heating the biocrude oils derived from the UBM and demineralized biomass to $800{ }^{\circ} \mathrm{C}$ leads to mass losses of approximately $88 \%$ and $85 \%$, respectively. All biocrude oil samples contain two mass loss peaks. The first peaks were found at $265{ }^{\circ} \mathrm{C}-270{ }^{\circ} \mathrm{C}$, and the second peaks were found at $390{ }^{\circ} \mathrm{C}-480{ }^{\circ} \mathrm{C}$. It is also shown that there were decreases in the heights of the first peaks and corresponding increases in the heights of the second peaks for the AA- and FA-derived biocrude oils, indicating that there was some trade-off between the biocrude oil quality and biocrude oil yield.

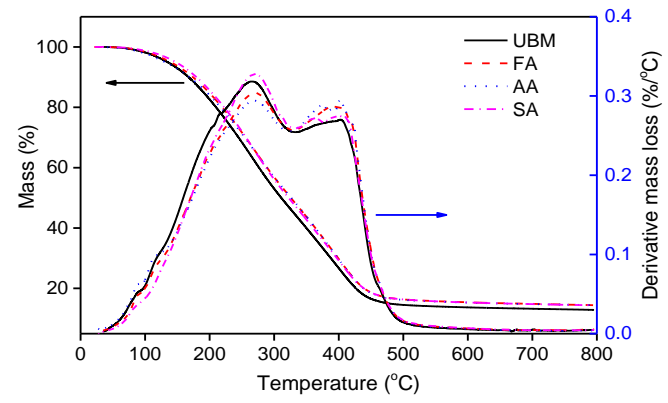

Figure 4. Thermogravimetric analysis (TGA)-DTG curves recorded for the biocrude oil samples derived from the HTL of untreated and acid-treated biomass. UBM: untreated biomass, AA: acetic acid, FA: formic acid, and SA: sulfuric acid

The simulated boiling point distributions of the biocrude oil samples are presented in Table 3. The results indicate that the biocrude oil fraction in the light and medium boiling point range $\left(<300{ }^{\circ} \mathrm{C}\right)$ are lower in the biocrude oil derived from demineralized biomass ( 43\%) compared to that from UBM $(47.02 \%)$. The TGA data also reveals that the GC-MS analysis was conducted only on the characterized part of the biocrude samples due to the temperature limitation of the GC oven, which was $310^{\circ} \mathrm{C}$.

Table 3. The simulated boiling point distribution of the biocrude oils obtained from the HTL of the untreated and demineralized WAB

\begin{tabular}{|c|c|c|c|c|c|}
\hline $\begin{array}{l}\text { Boiling point range } \\
\left({ }^{\circ} \mathrm{C}\right)\end{array}$ & Coke oil typical application [23] & UBM & AA & FA & SA \\
\hline $25-110$ & Bottle gas and chemicals & 2.53 & 2.96 & 2.25 & 1.75 \\
\hline $110-200$ & Gasoline & 14.88 & 13.06 & 13.06 & 12.63 \\
\hline $200-300$ & Jet fuel, fuel for stoves, and diesel oil & 29.60 & 27.12 & 27.86 & 29.53 \\
\hline $300-400$ & $\begin{array}{l}\text { Lubrication oil for engines and fuel for ships and } \\
\text { machines }\end{array}$ & 26.26 & 27.15 & 27.07 & 26.86 \\
\hline $400-550$ & Lubricants, candles, and fuel for ships & 12.69 & 14.06 & 13.98 & 13.50 \\
\hline $550-700$ & Fuel for ships, factories, and central heating & 0.77 & 0.86 & 0.90 & 0.94 \\
\hline $700-800$ & Asphalt and roofing & 0.39 & 0.36 & 0.45 & 0.42 \\
\hline$>800$ & Residues & 12.87 & 14.43 & 14.42 & 14.37 \\
\hline
\end{tabular}




\section{Conclusions}

Demineralization treatment by acid leaching effectively improves the conversion of WAB into biocrude oil by $23 \%-49 \%$ via HTL. This treatment did not improve the HHV of the biocrude oil ( 35 $\mathrm{MJ} / \mathrm{kg}$ ) generated from WAB. However, in comparison with the UBM (27.58\%), it improved the ER of the biocrude oil by $23 \%-42 \%$. The highest ER value $(41.83 \% \pm 1.87 \%)$ was obtained from the FA-treated biomass. GC-MS analysis showed that the amount of oxygenates in both AA and FA biocrude oils are lower compared to that of SA and UBM, indicating the improved fuel properties in terms of storage stability. The TGA data showed that the biocrude oils derived from the UBM and treated biomass may be used as jet fuel and lubricating oil.

\section{Acknowledgements}

The first author gratefully acknowledges the financial support from the ERDT Scholarship Sandwich Program (Philippines), which sponsored the living expense while the author was studying abroad. The author would also like to thank the Department of Agricultural and Biological Engineering, University of Illinois Urbana-Champaign, USA for providing the experiment facilities and expenses for the research. TGA was performed in part at the Frederick Seitz Materials Research Laboratory Central Facilities, University of Illinois Urbana-Champaign. Further, the author would like to thank Peng Zhang for his kind help.

\section{References}

[1] N. Abdel-Raouf, A. A. Al-Homaidan, and I. B. M. Ibraheem, "Microalgae and wastewater treatment," Saudi J. Biol. Sci., vol. 19, no. 3, pp. 257-275, 2012.

[2] Y. Zhou, L. Schideman, G. Yu, and Y. Zhang, "A synergistic combination of algal wastewater treatment and hydrothermal biofuel production maximized by nutrient and carbon recycling," Energy Environ. Sci., vol. 6, no. 12, p. $3765,2013$.

[3] C. Tian, B. Li, Z. Liu, Y. Zhang, and H. Lu, "Hydrothermal liquefaction for algal biorefinery: A critical review," Renew. Sustain. Energy Rev., vol. 38, pp. 933-950, 2014.

[4] G. Yu, "Hydrothermal liquefaction of low-lipid microalgae to Produce bio-crude oil," University of Illinois at UrbanaChampaign, 2012.

[5] K. L. Chin, P. S. H’ng, M. T. Paridah, K. Szymona, M. Maminski, S. H. Lee, W. C. Lum, M. Y. Nurliyana, M. J. Chow, and W. Z. Go, "Reducing ash related operation problems of fast growing timber species and oil palm biomass for combustion applications using leaching techniques," Energy, vol. 90, pp. 622-630, 2015.

[6] T. Ma, C. Fan, L. Hao, S. Li, W. Song, and W. Lin, "Fusion characterization of biomass ash," Thermochim. Acta, vol. 638, pp. 1-9, 2016.

[7] B. Melissari, "Ash related problems with high alkalii biomass and its mitigation - experimental evaluation," Mem. Investig. en Ing., vol. 12, no. 12, pp. 31-44, 2014.

[8] Y. Niu, H. Tan, and S. Hui, “Ash-related issues during biomass combustion: Alkali-induced slagging, silicate meltinduced slagging (ash fusion), agglomeration, corrosion, ash utilization, and related countermeasures," Prog. Energy Combust. Sci., vol. 52, pp. 1-61, 2016.

[9] S. Q. Turn, C. M. Kinoshita, and D. M. Ishimura, "Removal of inorganic constituents of biomass feedstocks by mechanical dewatering and leaching," Biomass and Bioenergy, vol. 12, no. 4, pp. 241-252, 1997.

[10] K. Wang, J. Zhang, B. H. Shanks, and R. C. Brown, "The deleterious effect of inorganic salts on hydrocarbon yields from catalytic pyrolysis of lignocellulosic biomass and its mitigation,” Appl. Energy, vol. 148, pp. 115-120, 2015.

[11] W. T. Chen, Y. Zhang, J. Zhang, L. Schideman, G. Yu, P. Zhang, and M. Minarick, "Co-liquefaction of swine manure and mixed-culture algal biomass from a wastewater treatment system to produce bio-crude oil," Appl. Energy, vol. 128, pp. 209-216, 2014.

[12] X. Liu and X. T. Bi, "Removal of inorganic constituents from pine barks and switchgrass," Fuel Process. Technol., vol. 92, no. 7, pp. 1273-1279, 2011. 
[13] T. Wigley, A. C. K. Yip, and S. Pang, "The use of demineralisation and torrefaction to improve the properties of biomass intended as a feedstock for fast pyrolysis," J. Anal. Appl. Pyrolysis, vol. 113, pp. 296-306, 2015.

[14] L. M. Díaz-Vázquez, A. Rojas-Pérez, M. Fuentes-Caraballo, I. V. Robles, U. Jena, and K. C. Das, "Demineralization of Sargassum spp. macroalgae biomass: Selective hydrothermal liquefaction process for bio-oil production,” Front. Energy Res., vol. 3, no. February, pp. 1-11, 2015.

[15] C. Yu, P. Thy, L. Wang, S. N. Anderson, J. S. Vandergheynst, S. K. Upadhyaya, and B. M. Jenkins, "Influence of leaching pretreatment on fuel properties of biomass," Fuel Process. Technol., vol. 128, pp. 43-53, 2014.

[16] A. B. Ross, P. Biller, M. L. Kubacki, H. Li, A. Lea-Langton, and J. M. Jones, "Hydrothermal processing of microalgae using alkali and organic acids," Fuel, vol. 89, no. 9, pp. 2234-2243, 2010.

[17] D. R. Vardon, B. K. Sharma, J. Scott, G. Yu, Z. Wang, L. Schideman, Y. Zhang, and T. J. Strathmann, "Chemical properties of biocrude oil from the hydrothermal liquefaction of Spirulina algae, swine manure, and digested anaerobic sludge," Bioresour. Technol., vol. 102, no. 17, pp. 8295-8303, 2011.

[18] K. Hammes, R. J. Smernik, J. O. Skjemstad, A. Herzog, U. F. Vogt, and M. W. I. Schmidt, "Synthesis and characterisation of laboratory-charred grass straw (Oryza sativa) and chestnut wood (Castanea sativa) as reference materials for black carbon quantification," Org. Geochem., vol. 37, no. 11, pp. 1629-1633, 2006.

[19] C. Tian, Z. Liu, Y. Zhang, B. Li, W. Cao, H. Lu, N. Duan, L. Zhang, and T. Zhang, "Hydrothermal liquefaction of harvested high-ash low-lipid algal biomass from Dianchi Lake: Effects of operational parameters and relations of products," Bioresour. Technol., vol. 184, pp. 336-343, 2015.

[20] Y. Guo, T. Yeh, W. Song, D. Xu, and S. Wang, "A review of bio-oil production from hydrothermal liquefaction of algae," Renew. Sustain. Energy Rev., vol. 48, pp. 776-790, 2015.

[21] U. Jena, K. C. Das, and J. R. Kastner, "Effect of operating conditions of thermochemical liquefaction on biocrude production from Spirulina platensis," Bioresour. Technol., vol. 102, no. 10, pp. 6221-6229, 2011.

[22] S. S. Toor, L. Rosendahl, and A. Rudolf, "Hydrothermal liquefaction of biomass: A review of subcritical water technologies,” Energy, vol. 36, no. 5, pp. 2328-2342, 2011.

[23] J. G. Speight and J. Speight, Handbook of Petroleum Analysis. Wiley-Interscience, Hoboken, NJ, 2002.

\section{Appendix A: A list of the major compounds in the biocrude oil samples identified using GC-MS.}

\begin{tabular}{|c|c|c|c|c|}
\hline \multirow{2}{*}{ Compounds } & \multicolumn{2}{|c|}{$\%$ Relative peak area } & \multirow[b]{2}{*}{ FA } & \multirow[b]{2}{*}{$\mathrm{SA}$} \\
\hline & UBM & AA & & \\
\hline Acetamide, n-isobutyl- & 1.63 & 1.71 & 1.67 & 1.36 \\
\hline 4-Methylphenol (p-Cresol) & 1.00 & & 1.37 & \\
\hline 2,5-Pyrrolidinedione, 1-methyl- & 1.40 & 1.04 & 1.66 & \\
\hline N-(3-Methylbutyl)acetamide & 1.47 & 1.43 & 1.09 & 1.42 \\
\hline Acetamide, n-(3-methylbutyl)- & 2.99 & 3.50 & 1.79 & 2.19 \\
\hline $\mathrm{N}$-acetylpyrrolidine & 3.19 & 5.15 & 3.39 & 2.70 \\
\hline 2-Piperidinone & 1.16 & & & \\
\hline 2,4-Octadienoic acid, 6-methyl-, 2,3-dihydroxypropyl & 1.10 & & & \\
\hline Ethyldimethylthiophene & & 1.02 & & \\
\hline Indole & 3.47 & 3.21 & 3.33 & 2.81 \\
\hline 5-Methyl-1H-Indole & 1.70 & 1.82 & 1.90 & 1.68 \\
\hline 1-(Dimethylamino)-3-(dicyanomethylene)cyclopropene & 1.18 & 1.31 & 1.26 & 1.08 \\
\hline Cyclopentadecane & 1.34 & & & 1.61 \\
\hline 1-Hydroxytetradecane & & 1.07 & 1.48 & \\
\hline Acetamide, n-phenethyl- & 3.42 & 5.81 & 3.05 & 3.35 \\
\hline 1-Heptadecene & & & & 1.17 \\
\hline Cyclopentadecane & & & 1.06 & \\
\hline Heptadecane & 2.16 & 1.58 & 1.78 & 1.79 \\
\hline 1-Nonadecene & 1.35 & & 1.17 & 1.45 \\
\hline Acetic acid, 3,7,11,15-tetramethyl-hexadecyl ester & 1.28 & 1.43 & 1.26 & 1.75 \\
\hline Hexadecane, 2,6,10,14-tetramethyl- & 1.11 & 1.19 & 1.42 & 1.56 \\
\hline (2e)-3,7,11,15-Tetramethyl-2-Hexadecene & 1.86 & 1.42 & 1.67 & 1.68 \\
\hline Methyl n-pentadecanoate & 5.43 & 3.26 & 3.39 & 4.92 \\
\hline 2-hexadecene, 3,7,11,15-tetramethyl-, & 6.94 & 5.31 & 5.17 & 5.69 \\
\hline 2-Hexadecene, 3,7,11,15-tetramethyl-, [R-[R*, R*-(E)]]- & 7.55 & 7.52 & 5.89 & 7.42 \\
\hline 3,7,11,15-Tetramethyl-2-hexadecen-1-ol & 2.61 & & & 1.61 \\
\hline Cyclopentadecane & & 1.44 & & \\
\hline Pentadecanoic acid, methyl ester & 3.50 & 3.28 & 3.63 & 4.48 \\
\hline
\end{tabular}


3,9-Diazatricyclo[7.3.0.0(3,7)]dodecan-2,8-dione

3-Isobutylhexahydropyrrolo[1,2-a]pyrazine-1,4-dione

9H-Pyrido[3,4-b]indole, 1-methyl-

1-Hexadecanol, 3,7,11,15-tetramethyl-

Hexadecanamide

Palmitic acid, butyl ester

N-Methylhexadecanamide

N,N-Dimetylpalmitamide

Stearic acid, butyl ester

Octadecanamide, N-butyl-

5-(4-Acetamido-2-methoxyphenyl)-4-isopropenyltropolone

Hexadecanoic acid, pyrrolidide

Deoxyisopodophyllotoxin

Dihydrocholesterol

Stigmastanol

Stigmastan-3-ol
1.98

1.28

2.18

1.41

2.11

2.56

1.58

.

1.63

1.11

1.25

1.52

$$
1.37
$$

2.96

2.04

1.92

1.44

1.89

1.11

1.82

2.18

1.42

1.72

2.97

1.88

1.36

1.03

2.43

1.05

2.18

2.60

1.09

76.61

2.39

1.17

2.54

1.02

1.06

1.58

1.78

71.51

2.24

1.42

1.54

2.36 